\section{Three Mimic Mutants for Spindly Branch in Common Bean and Tests for Linkage with Other Mutants}

\author{
Mark J. Bassett' \\ Vegetable Crops Department, IFAS, University of Florida, Gainesville, \\ FL 32611
}

Additional index words. Phaseolus vulgaris, chromosome structure, inheritance, induced mutation

\begin{abstract}
The inheritance of two new induced mutations for spindly branch was investigated in common bean (Phaseolus vulgaris $L$.). Each mutant was found to be controlled by a recessive gene. Allelism tests were performed beween a previously reported spindly branch mutant $(s b)$ and the two new spindly branch mutants; the new mutants were found to be nonallelic to $s b$ and to each other. The gene symbols $s b-2$ and $s b-3$ are proposed for the new mutants. Repulsion phase $F_{2}$ linkage tests were made for all nine combinations of reclining foliage $(r f)$ and $s b$ among the two mimic mutant series $r f, r f-2, r f-3$ and $s b, s b-2, s b-3$. No linkages were detected.
\end{abstract}

The first spindly branch mutant in common bean was reported by Awuma and Bassett (1988). Subsequently, two more induced mutants of the spindly branch phenotype have been found. Bassett and Awuma (1989) previously demonstrated that a series of three mimic mutants for reclining foliage $(r f, r f$ 2 , and $r f-3$ ) exists in common bean. It is interesting to speculate that there may be a relationship between the structure of the genome and the existence of three mimic mutants. I hypothesize that there is a large chromosomal region that is duplicated three times in the genome of common bean. The existence of such a region could explain the appearance of mimic mutants in triplets on nonallelic genes. The concept that multiple genes have the same effect in common bean is not new. For example, Lamprecht (1932) reported the "polymeric" genes $E a$ and $E b$ for "flat" pod, i.e., elliptical in cross-section rather than round. Lamprecht (1953) elaborated these ideas more fully in his extensive genetic work with garden pea (Pisum sativum L.). He believed that each of the seven chromosomes of pea had one or two small regions that are homologous with corresponding regions in other chromosomes. Thus, these homologous regions in nonhomologous chromosomes carry the same genes. Identical genes appearing in two nonhomologous chromosomes are called polymeric genes. This paper presents results of inheritance studies and allelism tests among the three mimic mutants for spindly branching and results of tests for linkage between loci controlling reclining foliage and spindly

Received for publication 10 Oct. 1989. Fla. Agr. Expt. Sta. Journal Series no. R-00158. This research was supported in part by funds from a USDA Special Grants program (Section 406). The cost of publishing this paper was defrayed in part by the payment of page charges. Under postal regulations, this paper therefore must be hereby marked advertisement solely to indicate this fact.

${ }^{\text {'}}$ Professor of Horticulture. branching.

The dry bean lines used in this study are all breeding lines released by the Tropical Agricultural Research Station at Mayaguez, Puerto Rico. These lines have small black seeds and the half-runner habit. Dry seed of 182-1, B-351, and B-128 were treated with 21) $\mathrm{kR}$ of gamma radiation and planted in the field in 1982 to produce $\mathbf{M}_{2}$ seed. Mature seed were harvested from individual $\mathrm{M}_{1}$ plants and planted in $>700$ separate $\mathbf{M}_{2}$ plots in the field in 1983. These populations were screened at weekly intervals for mutant plants. Plots 3-99, 3-100, 3-146, 3-296 segregated for the spindly branch marker mutant. The spindly branch mutant from 3-99 has been $s b^{2}, 3-100$, and 3-146.

${ }^{y} 182-1$ is a breeding line with normal branch development. $182-1$ and 3-146 $(s b-3) \times 182-1$. previously reported (Awuma and Bassett, 1988) and was given the gene symbol $s b$. The spindly branch mutant in 3-296 will not be discussed in this paper.

The mutants 3-100 and 3-146 were crossed as female parents with $182-1$ and $F_{2}$ seed was produced. The $\mathrm{F}_{2}$ seed was planted in the field and the plants were classified for normal and mutant phenotypes. Seed from 16 normal $\mathrm{F}_{2}$ plants were randomly selected in each cross for use in $\mathrm{F}_{3}$ progeny tests, to be planted in the field the following year and classified as before.

The lines 3-100, 3-146, and a stock carrying $s b$ were crossed in all combinations to perform tests for allelism. The $F_{1}$ was grown in the greenhouse and classified for normal and mutant phenotype. $\mathrm{F}_{2}$ seed from normal plants was planted in the field-and the populations were classified as before.

The mutants $r f, r f-2, r f-3, s b, 3-100$, and 3-146 have all been partly converted to the genotype of breeding line 5-593, i.e., they are in $\mathrm{BC}_{1}$ to 5-593 with strong selection for phenotypic similarity to 5-593. Stocks in $\mathrm{BC}_{1}$ for each of the six mutants were crossed in the nine possible combinations of $r f$ and $s b$ mutants. The $\mathrm{F}_{2}$ seed was planted in the field in 1989 and the nine populations were classified for four phenotypic classes-normal, the two single mutants, and the double mutant classes.

The crosses 3-100 $\times 182-1$ and 3-146 $\times$ 182-1 segregated in $F_{2}$ for normal and spindly branch plants in the ratio of 3 normal : 1 spindly branch (Table 1). This segregation ratio is consistent with the hypothesis that both spindly branch mutants are controlled by a recessive gene. This hypothesis was tested in $\mathrm{F}_{3}$ progeny tests of normal $\mathrm{F}_{2}$ se-

Table 1. Inheritance and allelism tests for three mimic mutants of the spindly branch type, including

\begin{tabular}{|c|c|c|c|c|c|c|}
\hline \multirow[b]{2}{*}{ Cross } & \multirow[b]{2}{*}{ Generation } & \multicolumn{2}{|c|}{$\begin{array}{l}\text { Phenotypic } \\
\text { classification }\end{array}$} & \multirow{2}{*}{$\begin{array}{l}\text { Ratio } \\
\text { tested }\end{array}$} & \multirow{2}{*}{$\begin{array}{c}\chi^{2} \\
\text { value }\end{array}$} & \multirow{2}{*}{$\begin{array}{c}P \\
\text { value }\end{array}$} \\
\hline & & Normal & Mụtant & & & \\
\hline $3-100 \times 182-1^{y}$ & $\mathrm{~F}_{2_{-}}$ & 325 & 122 & $3: 1$ & 1.25 & 0.26 \\
\hline $3-146 \times 182-1$ & $\mathrm{~F}_{2}$ & 227 & 74 & $3: 1$ & 0.027 & 0.87 \\
\hline \multirow[t]{2}{*}{$3-100 \times s b$} & $F_{1}$ & 12 & 0 & & & \\
\hline & $\mathrm{F}_{2}$ & 333 & 246 & $9: 7$ & 0.375 & 0.54 \\
\hline \multirow[t]{2}{*}{$s b \times 3-146$} & $F_{1}$ & 12 & 0 & & & \\
\hline & $\mathrm{F}_{2}$ & 277 & 211 & $9: 7$ & 0.05 & 0.82 \\
\hline \multirow[t]{2}{*}{$3-100 \times 3-146$} & $F_{1}$ & 15 & 0 & & & \\
\hline & $F_{2}$ & 411 & 283 & 9:7 & 2.49 & 0.11 \\
\hline
\end{tabular}

The inheritance of $s b$ was previously reported (Awuma and Bassett, 1988).

Table 2. $\mathrm{F}_{3}$ progeny tests of randomly selected normal $\mathrm{F}_{2}$-segregants from the crosses 3-100 $(s b-2) \times$

\begin{tabular}{|c|c|c|c|c|}
\hline \multirow{2}{*}{$\begin{array}{l}\text { Spindly } \\
\text { mutant }\end{array}$} & \multicolumn{2}{|c|}{ Classification of $F_{3}$ progenies } & \multirow{2}{*}{$\begin{array}{c}x^{2} \\
2: 1\end{array}$} & \multirow{2}{*}{$\begin{array}{c}P \\
\text { value }\end{array}$} \\
\hline & Segregating ${ }^{2}$ & Nonsegregating & & \\
\hline $3-100$ & 13 & 3 & 1.527 & 0.22 \\
\hline \multirow[t]{3}{*}{$3-146$} & 11 & 5 & 0.031 & 0.86 \\
\hline & \multicolumn{2}{|c|}{ Phenotypic classification $^{2}$} & $x^{2}$ & $P$ \\
\hline & Normal & Spindly & $3: 1$ & value \\
\hline $3-100$ & 253 & 77 & 0.489 & 0.48 \\
\hline $3-146$ & 193 & 78 & 2.068 & 0.15 \\
\hline
\end{tabular}

${ }^{2}$ Data for all-segregating $F_{3}$ progenies were combined for each mutant. 
Table 3. Repulsion linkage tests involving $\mathrm{F}_{2}$ populations from nine cross combinations among $r f$, rf2, $r j-3, s b, s b-2$, and $s b-3$

\begin{tabular}{|c|c|c|c|c|c|c|}
\hline \multirow{2}{*}{$\frac{\text { Cross }}{\text { Mut } 1 \times \text { Mut } 2}$} & \multicolumn{4}{|c|}{ Phenotypic classification } & \multirow{2}{*}{$\begin{array}{c}\text { Linkage }^{z} \\
\chi^{2}\end{array}$} & \multirow{2}{*}{$\begin{array}{c}P \\
\text { value }\end{array}$} \\
\hline & $\mathrm{N}$ & Mutant 1 & Mutant 2 & Double & & \\
\hline$\overline{r f \times s b}$ & 426 & 125 & 126 & 46 & 12.829 & $<0.001$ \\
\hline$r f \times s b-2$ & 430 & 122 & 146 & 49 & 0.568 & 0.56 \\
\hline$r f \times s b-3$ & 415 & 124 & 140 & 45 & 0.071 & 0.79 \\
\hline$r f-2 \times s b$ & 401 & 137 & 147 & 49 & 0.001 & 0.97 \\
\hline$r f-2 \times s b-2$ & 431 & 128 & 141 & 44 & 0.022 & 0.88 \\
\hline$r f-2 \times s b-3$ & 451 & 128 & 106 & 38 & 0.966 & 0.33 \\
\hline$r f-3 \times s b$ & 417 & 151 & 124 & 25 & 5.606 & 0.02 \\
\hline$r f-3 \times s b-2$ & 413 & 124 & 140 & 34 & 0.766 & 0.38 \\
\hline$r f-3 \times s b-3$ & 403 & 129 & 157 & 59 & 0.613 & 0.43 \\
\hline
\end{tabular}

${ }^{2}$ The expected values were calculated with contingency tables, and linkage $X^{2}$ was calculated with the formula $\quad\left(\mid \text { otss. }{ }^{2}=\exp . \mid-1 / 2\right)^{2}$ exp.

gregants. For both mutants, the $\mathrm{F}_{3}$ plots were of only two types, those that were nonsegregating (only normal plants) and those that segregated again for normal and spindly branch plants. A satisfactory fit was found for the ratio 2 segregating : 1 nonsegregating among $\mathrm{F}_{3}$ plots (Table 2). When data from all segregating $F_{3}$ plots were combined for each mutant, an analysis showed a good fit to a ratio of 3 normal :1 mutant (Table 2). Thus, the hypothesis is supported that a single recessive gene controls the inheritance of spindly branch in 3-100 and 3-146.

The question remains whether the 3-100 and 3-146 spindly branch mutants are new mutants at $s b$ or are mutants at genetic loci other than $s b$. The $\mathrm{F}_{1}$ progeny from the crosses $3-100 \times s b, s b \times 3-146$, and 3-100 $\times 3-146$ were all normal (Table 1 ). The $F_{2}$ progeny from the same three crosses gave a satisfactory fit for a segregation ratio of 9 normal : 7 mutant (Table 1). The spindly branch mutants 3-100 and 3-146 are clearly nonallelic with each other and with $s b$. It was not possible to obtain a 9:3:3:1 ratio in $F_{2}$ because the spindly mutants in all three combinations were too similar in appearance. to make the distinction between the two. I propose the gene symbols $s b-2$ for 3-100 and $s b-3$ for 3146 , indicating a series of mimic marker genes that are nonallelic. In pure stands one can see subtle differences between $r f, r f-2$, and $r f-3$, but $s b, s b-2$, and $s b-3$ are so similar that they cannot be distinguished even in pure stands.

Repulsion phase linkage tests were made in $\mathrm{F}_{2}$ populations involving all nine combinations of $r f$ and $s b$. The expected values used in the $X^{2}$ tests were calculated with contingency tables, and linkage $X^{2}$ was calculated with the formula $X^{2}=1$ obs. - exp. $-1 / 2)^{2}$ exp. All but two of the populations showed nonsignificant deviation $(\mathrm{P}>$ 0.05 ) from the expected values for independence (Table 3 ), and they clearly show no sign of genetic linkage between the marker genes. For the two deviant populations, orthogonal analysis was performed using the formulas of Mather (1951) to separate variation due to linkage from variation due to deviation of single gene ratios from the expected 3:1. For the cross $r f \times s b$ the linkage $X^{2}$ was not significant $\left(X^{2}=1.163, P=\right.$ $0.28)$. For the cross $r f-3 \times s b$ the linkage $X^{2}$ was significant $\left(X^{2}=5.19, P=0.02\right)$, but this was probably an artifact due to misclassification of some double mutants $(r f-3+$ $s b)$ as $r f$ single mutants and this distorted the apparent segregation ratio of $s b\left(X^{2} s b=6.807\right.$, $P=0.009$ ). As the data stand (Table 3), linkage was calculated using the maximumlikelihood method and formulas of Allard (1956), giving $\mathrm{CM}=41.95 \pm 3.04$. When one "corrects" this probable misclassifica- tion by subtracting 15 from the $r f-3$ value $(151-15=136)$ and adding these plants to the double mutant class $(25+15=40)$, a recalculation of linkage gives $\mathrm{CM}=49.89$ \pm 2.8 , which is not significant. Given these considerations, the apparent weak linkage between $r f-3$ and $s b$ is very dubious and should be disregarded. Thus, there is no indication of linkage disturbance of the segregation in any of the nine populations (Table 3).

The absence of linkage between any of the pairs of marker genes gives no support to the hypothesis that there is a large chromosomal region that is duplicated three times in the genome of common bean. However, it is possible that the hypothesis is still true, but the physical distance between $s b$ and $r f$ is too great to result in disturbed segregation ratios. An alternative hypothesis is that the three mimic mutants in each series are not on duplicated chromosome regions but produce proteins each of which will produce the same mutant phenotype if the protein is rendered nonfunctional by mutation. This question cannot be resolved until there is a more complete linkage map for common bean. I hope that the results presented here will stimulate additional linkage investigation.

\section{Literature Cited}

Allard, R.W. 1956. Formulas and tables to facilitate the calculation of recombination values in hereditary. Hilgardia 24:235-278.

Awuma, K. and M.J. Bassett. 1988. Addition of genes for dwarf seed $(d s)$ and spindly branch $(s b)$ to the linkage map of common bean. J. Amer. Soc. Hort. Sci. 113:464-467.

Bassett, M.J. and K. Awuma. 1989. Three mimic mutants for reclining foliage in common bean. HortScience 24:131-132.

Lamprecht, H. 1932. Beiträge zur Genetik von Phaseolas vulgaris. II. Uber Vererbung von Hiilsenfarbe and Hülsenform. Hereditas 16:295340.

Lamprecht, H. 1953. New and hitherto known polymeric genes of Pisum. Agr. Hort. Genet. 11:40-54.

Mather, K. 1951. The measurement of linkage in heredity. Methuen, New York. 